\title{
DETERMINAÇÃO EXPERIMENTAL DOS RAIOS CRISTALOGRÁFICOS DOS ÍONS SÓDIO E CLORETO
}

\author{
Matthieu Tubino* e José de Alencar Simoni \\ Instituto de Química, Universidade Estadual de Campinas, CP 6154, 13083-970 Campinas - SP, Brasil
}

Recebido em 14/6/06; aceito em 20/12/06; publicado na web em 25/9/07

\begin{abstract}
DETERMINATION OF THE CRYSTALLOGRAPHIC RADII OF SODIUM AND CHLORIDE IONS. This experiment, where very common materials and equipments are used, conducts to good and interesting results related to the ionic radii of sodium and chloride ions. It also offers an excellent opportunity to discuss the crystalline arrangement of solids and to apply simple mathematical tools for calculations. Other important concepts such as density, solubility and saturated solution are also used. The simplicity of the experiment creates an excellent opportunity for reasoning with the students about the technique.
\end{abstract}

Keywords: crystallographic radii; sodium chloride; solid density.

\section{INTRODUÇÃO}

Pode-se ver e tocar um pedaço de matéria com as nossas mãos. Em outras palavras, pode-se ver e tocar átomos, moléculas e íons... quando eles estão agregados formando uma peça de bom tamanho, suficiente para ser percebida pelos nossos sentidos. Contudo, não se pode ver ou tocar um átomo isolado, uma molécula ou um íon. Assim, usando alguns recursos do nosso corpo, também constituído de átomos, moléculas e íons, é possível tocar e ver uma "sociedade" atômica, molecular ou iônica, mas não é possível ver ou tocar os seus membros individualmente. Talvez devido a este fato é que se formou a idéia corrente de que só se pode perquirir a constituição da matéria usando aparelhos poderosos. Contudo, contrariamente a essa idéia, é possível imaginar como a matéria é constituída, usando a nossa capacidade de abstração, criando um modelo que a explique para depois verificar, com experimentos muito simples, a consistência do modelo proposto. É um esforço que vale a pena, mormente quando se trabalha com estudantes que estão ingressando na universidade. Se a discussão inicial e o experimento forem bem conduzidos, os resultados serão muito bons e melhor ainda será a reação dos alunos, que podem fazer uma grande descoberta no que diz respeito ao método científico.

Como, para a execução deste experimento, são usados materiais fáceis de serem obtidos, e considerando que vários dos nossos estudantes trabalharão futuramente como professores de Química no ensino médio, configura-se aqui mais um aspecto de importância, ou seja, o uso deste tipo de atividade experimental por futuros professores com os seus futuros alunos, sejam estes de escolas particulares ou da rede pública.

O trabalho aqui proposto oferece várias facetas que podem ser aproveitadas, também, por qualquer professor já em exercício. A execução do experimento e os possíveis tratamentos dos dados serão destacados ao longo do texto. A necessidade de se discutir com mais cuidado um dado conceito ou assunto será destacada com um sinal expresso (D). Esse conceito pode ser trabalhado, visando um melhor aproveitamento didático da atividade.

O objetivo final da parte experimental é a determinação do raio iônico (cristalográfico) dos íons sódio e cloreto. Porém, para se chegar a isso, são necessárias algumas conjecturas, associadas a conhe-

*e-mail: tubino@iqm.unicamp.br cimentos bem estabelecidos. Assim, deverão estar bem claros os conceitos de densidade, solubilidade, solução saturada, constante de Avogadro, massa molecular, massa molar, quantidade de substância, tamanho de átomos e de íons. Esta é uma ótima oportunidade para que alguns conhecimentos de trigonometria como, por ex., o Teorema de Pitágoras, possam ser relembrados ou sedimentados.

O modelo de "esferas rígidas" para representar os íons, com os seus respectivos tamanhos, deve ser bem discutido, pois é fundamental para o desenvolvimento do raciocínio. O arranjo destas esferas, como propõe o modelo de empacotamento denso, também é importante. Neste caso, em particular, podem ser usadas bolas de plástico de diversos tamanhos para representar os íons, o que permite a construção de modelos macroscópicos de estruturas cristalinas. Mesmo laranjas, maçãs, além de bolinhas de aço, de vidro, de argila ou de isopor, podem ser usadas. Uma pilha de laranjas arrumada em uma banca de feira (Figura 1), pode ser um bom motivo para uma discussão sobre a estrutura da matéria. Este tipo de atividade facilita muito a visualização do problema a ser tratado no experimento.

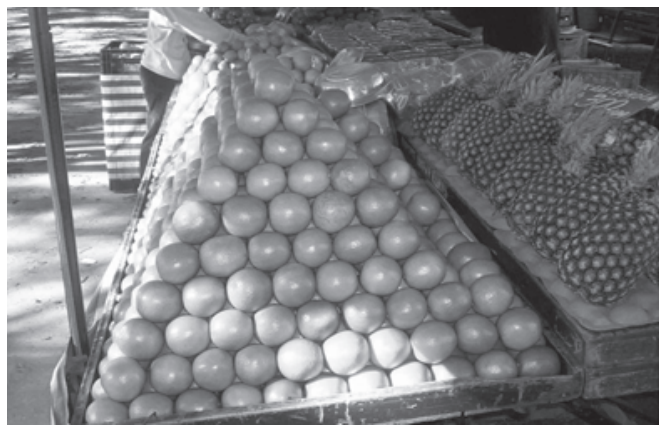

Figura 1. Um "arranjo" de laranjas em uma banca de feira. Como podemos relacionar este "arranjo" com o arranjo de átomos ou de íons em um cristal?

Em artigo publicado há mais de 20 anos $^{1}$ está descrito um experimento muito simples que é aplicado nos laboratórios de ensino de Química Geral de nossa Universidade, para alunos ingressantes. O procedimento experimental ali descrito, que também oferece excelentes resultados para a determinação da densidade do cloreto de sódio, faz uso de uma balança analítica, além de se usar um solvente orgânico (tolueno). 
Em outro artigo mais recente ${ }^{2}$ propusemos um trabalho experimental muito interessante, tanto pela facilidade de execução e baixíssimo custo como também pela qualidade dos resultados e pela riqueza da discussão. $\mathrm{O}$ experimento consiste na determinação dos raios atômicos dos metais: cobre, alumínio e ferro.

$\mathrm{Na}$ presente proposta volta-se ao cloreto de sódio. Desta vez, porém, a facilidade de conseguir o material que é utilizado permite a execução do experimento, em qualquer lugar, por menores que sejam os recursos materiais disponíveis. Esta nova situação justifica plenamente o presente artigo.

O caráter enriquecedor deste experimento é, em nossa opinião, tão grande, que julgamos ser muito oportuno o seu oferecimento a alunos ingressantes nas universidades, em disciplina de Química Geral Experimental.

\section{PARTE I - DISCUSSÃO E CONSTRUÇÃO DO MODELO DA ESTRUTURA CRISTALINA}

Na proposição de um modelo que possa ser aplicado à estrutura sub-microscópica de uma substância sólida, é necessário que se faça um exercício de imaginação, começando por observar o aspecto macroscópico da mesma e as suas propriedades. Não será feita aqui uma discussão muito detalhada do tema, já que em livros didáticos ${ }^{3-5}$ de Química Geral há bastante informação. Serão traçadas linhas gerais de raciocínio que podem ser usadas como pontos de partida pelos professores que vierem a adotar o presente experimento nas suas aulas de laboratório. Não queremos com isso oferecer uma receita de como conduzir a atividade. O objetivo é dar exemplos de como estimular a imaginação e a criatividade dos alunos.

\section{1- Como argumentar a favor de um modelo que sugere que o cloreto de sódio é formado por íons de cargas opostas?}

Sabe-se que uma solução aquosa de cloreto de sódio conduz a eletricidade, havendo ocorrência de reações químicas no ânodo e no cátodo. Também o sal fundido conduz a eletricidade com ocorrência de reações nos eletrodos. Tudo se passa como se o cloreto de sódio fosse constituído por partículas que contêm cargas, negativas e positivas. As positivas são atraídas pelo eletrodo negativo do circuito elétrico e as negativas pelo eletrodo positivo. Como, na eletrólise do sal fundido, o sódio aparece no pólo negativo, conclui-se que as suas "partículas", no sal, são positivas ou, em outras palavras, são íons positivos (cátions). Por sua vez, como o cloro aparece, nesta mesma eletrólise, no pólo positivo, conclui-se que as suas "partículas", no sal, são negativas ou, em outras palavras, são íons negativos (ânions). Deste modo, pode-se lançar a hipótese de que o cloreto de sódio sólido seja formado por cátions sódio e ânions cloreto (daí o nome cloreto de sódio) que se arranjam de modo equilibrado, levando à formação da substância que é observada macroscopicamente. Como partículas de mesma carga se repelem e de carga contrária se atraem, fica claro que na formação da estrutura do cloreto de sódio os cátions e os ânions devem obedecer a uma distribuição onde as atrações e as repulsões se compensam. Se este equilíbrio não ocorresse, haveria acúmulo de cargas de mesmo sinal em certas posições do material e se, apesar da proximidade de cargas de mesmo sinal, o sal se apresentasse com uma estrutura sólida, ele daria "choques", o que não se observa na realidade.

\section{2- Como será que os cátions e os ânions se arranjam, formando a estrutura do cloreto de sódio?}

A observação atenta mostra que cristais do cloreto de sódio (usar de preferência sal grosso, cujos cristais são suficientemente grandes para que sejam facilmente observados a olho nu, com uma lupa ou com microscópio de pequeno aumento) apresentam formatos regulares que lembram cubos ou, melhor, superposição de cubos. Em face de tal observação é possível imaginar que, se o aspecto macroscópico lembra uma superposição de cubos, esta aparência poderia ser o reflexo de um mesmo tipo de organização dos íons desde as dimensões sub-microscópicas. Em outras palavras, o arranjo de íons sódio e cloreto seguiria o formato de um cubo desde a menor unidade estrutural apresentando a proporção: $1 \mathrm{Na}^{+}$para $1 \mathrm{Cl}^{-}$. Esta unidade denomina-se de "cela unitária" (D).

3- Como será que os íons se arranjam para formar o cubo? Se cargas de mesmo sinal se repelem e as de diferentes sinais se atraem, como ficariam distribuídos os íons no cristal para que, num todo, a carga resultante seja zero?

Este problema pode ser trabalhado através de hipóteses. Sabe-se que a carga final de certa quantidade de cloreto de sódio é zero. Qual seria o menor agregado de $\mathrm{Na}^{+} \mathrm{e} \mathrm{Cl}^{-}$com carga zero? A resposta poderia ser: um conjunto "rígido" constituído por apenas um íon sódio e um íon cloreto (Figura 2). Assim, se ocorresse um arranjo tridimensional deste conjunto binário inicial, não apareceria o problema da repulsão dos íons com carga igual. No entanto, as propriedades do cloreto de sódio, como, por exemplo, o alto ponto de fusão, que indica ligações fortes na estrutura do cristal, não poderiam ser explicadas por esta suposição, pois as interligações entre os conjuntos binários iniciais $\left(\mathrm{Na}^{+} / \mathrm{Cl}^{-}\right)$seriam muito fracas devido à falta de cargas para a interação. Porém, se for imaginado um conjunto $\mathrm{NaCl}$ isolado, onde um outro $\mathrm{Na}^{+}$se aproxima do mesmo pelo lado do $\mathrm{Cl}^{-}$, pode-se supor que o $\mathrm{Na}^{+}$, devido a sua carga positiva, induzirá o aparecimento de carga parcial negativa no cloreto (não esquecendo que a carga do cloreto do conjunto $\mathrm{NaCl}$ contrabalança a carga do $\mathrm{Na}^{+}$). Com isso, sobraria carga positiva no sódio do conjunto, pela descompensação do equilíbrio de cargas, já que o cloreto teria "desviado" parte de sua carga negativa na direção do outro íon sódio que se aproximou. Assim, se um cloreto se aproximasse deste íon sódio inicial com carga parcial positiva haveria a formação de ligação. Este raciocínio pode ser repetido sistematicamente para todas as direções, formando o arranjo cristalino do cloreto de sódio, com interações interiônicas ao longo de todo o cristal, ou seja, em todas as direções. Deste modo, pode-se supor que o arranjo $\mathrm{NaCl}$, no cristal, seja uma unidade repetitiva que se forma pelo acúmulo tridimensional ordenado do mesmo.

\section{4- Imaginando o $\mathrm{NaCl}$ como constituído por duas esferas, uma representando o $\mathrm{Cl}^{-}$e o outro o $\mathrm{Na}^{+}$, qual seria o tama- nho relativo destas esferas?}

Olhando para a tabela periódica vê-se que o átomo de sódio apresenta 11 elétrons. Ao ser retirado 1 elétron para a formação do íon sódio, os 10 elétrons restantes devem ser mais atraídos pelo núcleo, uma vez que 11 prótons atraem agora 10 elétrons, conduzindo a uma diminuição do raio do íon em relação ao do átomo. Também a repulsão total entre os elétrons diminui por haver um elétron a menos. No caso do cloro há 17 elétrons no átomo. Ao receber 1 elétron adicional, na formação do íon cloreto, a atração do núcleo positivo sobre cada elétron individualmente é diminuída, além do aumento da repulsão entre os elétrons, o que conduz a uma expansão do tamanho do cloreto em relação ao cloro. Espera-se, assim, que o ânion cloreto seja maior que o átomo de cloro e também maior que o íon sódio. Com este raciocínio relativamente simples, chega-se à conclusão de que os íons sódio devem ser menores que os íons cloreto. Em termos pictóricos pode-se considerar o conjunto $\mathrm{NaCl}$ segundo a Figura 2. 
Figura 2. Um "conjunto" $\mathrm{NaCl}$

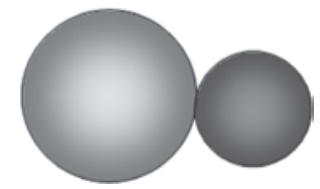

5- Como poderia se arranjar este conjunto para formar um cubo?

Para que seja mantido o equilíbrio de cargas no cristal, os ânions devem estar o mais próximo possível dos cátions e o mais longe possível dos outros ânions. Esta distribuição leva à situação óbvia de que os cátions devem estar mais longe dos cátions e mais próximos dos ânions. Usando-se objetos de tamanho apropriado (bolas plásticas, de madeira, argila etc.) pode-se chegar à situação de um cubo, o mais simples possível, segundo a Figura 3.

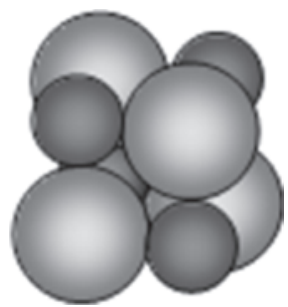

Figura 3. O arranjo cúbico "mais" simples

Se os constituintes deste cubo fossem todos iguais, teríamos o sistema cúbico primitivo ou simples. Como há íons cloreto e íons sódio, não se pode dar este nome.

Se cubos deste tipo forem associados em todas as direções para formar o retículo cristalino do $\mathrm{NaCl}$, será observado que, de fato, a cela unitária é o retículo cúbico de faces centradas (Figura 4; planos separados para melhor visualização). Para os cálculos do experimento proposto pode-se considerar qualquer dos dois arranjos citados (Figuras 3 e 4) que, em última análise, refletem a mesma estrutura. Se for usado o "arranjo cúbico mais simples" (Figura 3), será considerado o cubo circunscrito para que se tenha, na cela unitária, um número inteiro de íons, ou seja, quatro cloretos e quatro íons sódio, portanto, a proporção 1:1. Se for usado o cubo de faces centradas (Figura 4), considera-se o cubo que se constrói unindo-se os centros dos íons que estão nos vértices. Assim, têm-se, também, quatro íons cloreto e quatro íons sódio por cela unitária: os íons nos vértices são contados como $1 / 8$, nas arestas como $1 / 4$, nas faces como $1 / 2$ e no centro como 1 . Para a constituição da cela unitária da Figura 4 tem-se: os cloretos dos vértices $(8 \times 1 / 8=1$ cloreto $)$; os cloretos das faces $(6 \times 1 / 2=3$ cloretos $)$; no total há quatro cloretos na cela. Se fizermos o mesmo raciocínio para os íons sódio, teremos doze íons nas arestas $(12$ x 1/4 = três íons sódio), mais um no centro do cubo totalizando quatro íons sódio. As-

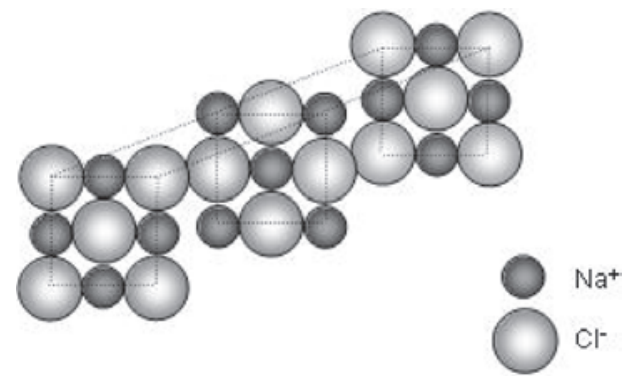

Figura 4. Sistema cúbico de faces centradas. Para efeito de visualização os três planos de íons que compõem a cela unitária são mostrados afastados. No modelo proposto eles se tocam sim, temos quatro cloretos para quatro íons sódio na cela unitária.

Para se determinar o tamanho da cela unitária e, a partir daí o comprimento das arestas e, portanto, a distância entre os íons sódio e cloreto, é necessário conhecer a densidade do cloreto de sódio. Sabendo-se que a densidade (propriedade intensiva (D)) de qualquer porção de um cristal de $\mathrm{NaCl}$, que obedeça à proporção 1 de $\mathrm{Cl}^{-}: 1$ de $\mathrm{Na}^{+}$e que tenha, no mínimo, o tamanho da cela unitária é sempre a mesma, pode-se calcular o volume referente à massa de uma cela unitária. Este procedimento está descrito na parte experimental que segue.

\section{PARTE II- DETERMINANDO A DENSIDADE DO CLORETO DE SÓDIO}

Para se determinar a densidade do $\mathrm{NaCl}$ não basta medir diretamente o volume que uma determinada massa do mesmo ocupa, devido ao ar que está interposto entre os cristais. Então, considerando um líquido no qual o $\mathrm{NaCl}$ não seja solúvel, pode-se usar do artifício de verificar o volume deslocado por uma determinada massa de $\mathrm{NaCl}$. Como o líquido ocupará todo o espaço entre os cristais, o volume deslocado de líquido será o volume efetivamente ocupado pela massa usada de sal.

Para fazer o experimento é possível usar solventes orgânicos ${ }^{1}$ onde o $\mathrm{NaCl}$ não é solúvel. No entanto, isto traz desvantagens como cheiro, toxicidade etc. O que se deseja fazer é um experimento muito simples, que necessite apenas de substâncias fáceis de se encontrar e que não sejam tóxicas. Também, os instrumentos usados devem ser muito simples, para que este experimento possa ser feito em qualquer lugar. Como isso pode ser feito?

Quanto ao solvente, o mais comum, barato e não tóxico é a água. Mas o cloreto de sódio é solúvel em água de modo que, a princípio, pode-se pensar que a mesma não pudesse ser usada. Mas há um modo de fazer isto: uma solução de cloreto de sódio saturada (D) não dissolve quantidades adicionais do sal. Assim, o líquido a se usar pode ser, perfeitamente, uma solução aquosa saturada de $\mathrm{NaCl}$.

No que se refere ao cloreto de sódio em si, que qualidade de produto poderia ser usada? Seria necessário, por ex., usar um reagente de grau analítico? O sal refinado de cozinha, por exemplo, vendido no mercado é de alta pureza. A adição de pequenas quantidades de outras substâncias ao mesmo, para finalidades diversas (D), poderia não afetar significativamente os resultados se o erro introduzido fosse muito pequeno (D), nas condições experimentais usadas. Isso é o que de fato se observa. Deste modo podese usar o sal refinado comprado no mercado em saquinhos de $1 \mathrm{~kg}$.

Verificamos experimentalmente que, entre diversas marcas comerciais, a massa de sal de cozinha refinado contida em um saquinho de $1 \mathrm{~kg}$ não varia muito. Isto é muito fácil de se verificar na prática. Basta pesar alguns saquinhos, que contenham 1 quilo de sal, em uma balança eletrônica de açougue (a menor divisão é $5 \mathrm{~g}$ ) e tirar a média dos valores obtidos. Usando uma balança semianalítica, foi observado um desvio médio (D) menor que $5 \mathrm{~g}$. Assim, se for considerada a massa nominal do sal contido em um saquinho (1000 g), o desvio médio (D) máximo introduzido por este fator será menor que $0,5 \%$. OBS: Neste caso, como o valor verdadeiro esperado é $1000 \mathrm{~g}$, o desvio também pode ser considerado como sendo o erro (D).

\section{Equipamento}

Para a determinação da densidade do cloreto de sódio é necessário medir o volume de líquido deslocado por uma massa conhecida deste sal. Um procedimento que pode ser usado é verificar o deslocamento de uma coluna de líquido, no qual o sal não é solú- 
vel, dentro de um recipiente transparente que permita a medição externa. Um frasco que serve perfeitamente para esta finalidade é uma garrafa PET de $2 \mathrm{~L}$ que apresente parte de seu corpo em formato de cilindro regular. Assim, se for medida a altura do deslocamento do líquido, e determinado o perímetro da circunferência da garrafa, pode-se calcular o volume deslocado.

Inicialmente coloca-se, na garrafa, uma quantidade de solução saturada de $\mathrm{NaCl}$ cujo nível atinja a parte de secção regular da mesma. Cerca de 0,5 L é suficiente.

O deslocamento do líquido, provocado pela adição do conteúdo de uma embalagem de sal, pode ser medido com uma régua. O perímetro da circunferência pode ser determinado usando-se uma tira de papel, um barbante ou mesmo uma fita métrica de costureira.

Para fazer as marcas na garrafa pode-se usar uma caneta de retro projetor ou, ainda, podem-se usar pequenos pedaços de fita adesiva.

Para se adicionar o sal e a água na garrafa pode-se usar um funil feito com a parte superior de uma garrafa PET cortada.

\section{Preparação da solução saturada de cloreto de sódio}

A solubilidade do cloreto de sódio em água, a $25^{\circ} \mathrm{C}$, é de 360 $\mathrm{g} / \mathrm{L}^{6}$. Assim, para a preparação de cerca de $0,5 \mathrm{~L}$ de solução saturada pode-se usar entre 20 e $25 \%$ do conteúdo do pacote.

Coloca-se o sal na garrafa com a ajuda do funil. Adiciona-se, a seguir, cerca de 0,5 L de água. Fecha-se a garrafa e agita-se vigorosamente durante $5 \mathrm{~min}$. Deixa-se decantar (D) o sólido e verifica-se se há corpo de fundo (D). Se não houver adiciona-se mais sal, repetindo o processo até que parte do sal não se dissolva.

Deixando a garrafa sobre uma mesa, marca-se o nível da solução. Adiciona-se, com cuidado, o sal contido em uma embalagem de 1000 g. Todo o sal deve ser transferido, caso contrário a relação massa/volume obtida não será a correta. Marca-se o novo nível da solução. Com isso calcula-se o volume deslocado e, daí, obtem-se a densidade do sal.

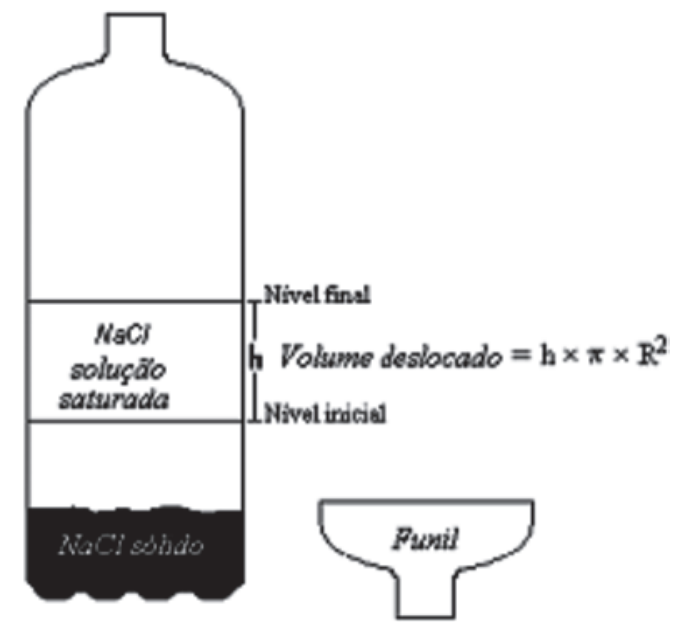

Figura 5. Esquema do aspecto do experimento no final, onde aparecem detalhes como o volume deslocado de solução e o funil confeccionado com parte de garrafa PET

\section{PARTE III - INTERPRETAÇÃO DOS RESULTADOS}

\section{Cálculo das dimensões da cela unitária}

Usando as considerações acima apresentadas, sobre a estrutura do $\mathrm{NaCl}$, são feitos cálculos de modo a obter a distância entre os centros de um íon sódio e do íon cloreto mais próximo.

No sistema cúbico em que o cloreto de sódio se apresenta, há quatro íons sódio e quatro íons cloreto na cela unitária.
Sendo a densidade determinada experimentalmente igual a $\rho$, em $\mathrm{g} / \mathrm{cm}^{3}$, calcula-se o volume ocupado por 1,00 mol de $\mathrm{NaCl}$ (volume molar).

Volume de $1,00 \mathrm{~mol}$ de $\mathrm{NaCl}=\frac{58,443 \mathrm{~g} \mathrm{NaCl}}{\rho}$

A partir deste valor calcula-se o volume da cela unitária, pois 1,00 mol de $\mathrm{NaCl}$ contém $6,02 \times 10^{23}$ "conjuntos $\mathrm{NaCl}$ ". Como para formar uma cela unitária (cubo de faces centradas) são necessários quatro destes "conjuntos", chega-se à conclusão que:

Volume da cela unitária $=\frac{\text { Volume molar } \times 4}{6,02 \times 10^{23}}$

Como se trata com um cubo, a aresta é igual à raiz cúbica do volume. No modelo considerado, a aresta corresponde à soma do diâmetro do íon cloreto com o diâmetro do íon sódio (Figura 4) ou, em outras palavras, à soma de dois raios do íon sódio com dois raios do íon cloreto.

\section{Como estimar os raios do íon cloreto e do íon sódio}

Observando o sistema cúbico de faces centradas e admitindo a Figura 4 como sendo uma representação adequada da cela unitária do cloreto de sódio, vê-se que os íons cloreto, ao longo da diagonal da face, não se tocam (isto é verdadeiro do ponto de vista geométrico e também na concepção do modelo químico proposto). No entanto, admitindo-se inicialmente que eles se tocam, pode-se calcular um valor "superestimado" para o raio do cloreto. Isto pode ser feito usando-se a relação de Pitágoras e o valor da aresta. Para a densidade correta do $\mathrm{NaCl}\left(2,17 \mathrm{~g} \mathrm{~cm}^{-3}\right)^{6}$, o valor da aresta é de $566 \mathrm{pm}$, o que leva a um valor superestimado de 200 picometros para o raio do cloreto. Isto conduz a um valor "subestimado", de aproximadamente $80 \mathrm{pm}$ para o raio do íon sódio, calculado a partir do valor da aresta.

Se, por outro lado, for admitido que os dois íons (sódio e cloreto) possuem o mesmo raio (agora seria uma outra situação onde os íons estariam se tocando pela aresta; verifique este modelo na Figura 6), chega-se a um valor aproximado de $141 \mathrm{pm}$ para o raio do cloreto.

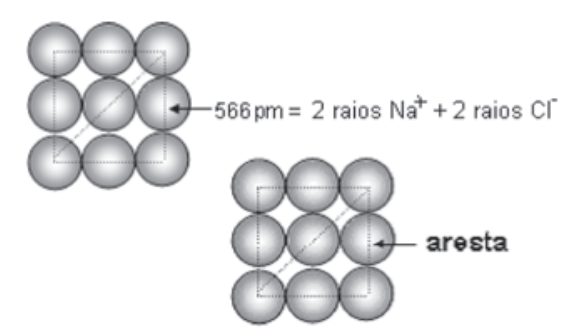

Figura 6. Modelo onde hipoteticamente os dois íons teriam o mesmo tamanho

Assim, o raio do cloreto deve estar entre 141 e 200 pm, enquanto que o raio do íon sódio deverá estar entre 80 e 141 pm. Usando-se os valores médios, como uma primeira aproximação, tem-se 170 pm para o cloreto e 110 pm para o sódio. Comparando esses valores com os da literatura (sódio 99 pm e cloreto 181 pm) ${ }^{6}$ vemos que a aproximação feita é muito boa, considerando a simplicidade do experimento. Na literatura são encontrados valores variáveis, embora muito próximos entre si, para os raios cristalográficos dos íons dos metais alcalinos e dos haletos. Aqui foram considerados os valores que são citados com mais freqüência. Esta variação, longe de trazer problemas na discussão dos dados obtidos com o experimento realizado, a enriquece, pois oferece 
a oportunidade de mostrar, aos estudantes, como os resultados experimentais dependem de vários fatores, dentre eles do modelo proposto e do método experimental utilizado.

Um excelente experimento poderia ser feito com o iodeto de lítio, já que, neste caso, o ânion é muito maior que o cátion. Esta relação de tamanho dos raios permite calcular o raio do iodeto $(220 \mathrm{pm})^{6} \mathrm{e}$, portanto, o do lítio $(59 \mathrm{pm})^{6}$. Infelizmente o iodeto de lítio é muito higroscópico, o que dificulta a realização da experiência, além do seu elevado preço.

Uma outra possibilidade seria obter a densidade do iodeto de lítio na literatura $\left(4,06 \mathrm{~g} \mathrm{~cm}^{-3}\right)^{6}$, aplicar o raciocínio exposto acima, obtendo-se com isto o raio do íon lítio. A seguir, usando-se o mesmo procedimento ao cloreto de lítio $\left(2,07 \mathrm{~g} \mathrm{~cm}^{-3}\right)^{6}$, pode-se obter o raio do cloreto. Continuando, é possível determinar o raio do íon sódio.

Feitas as determinações, é interessante confrontar os resultados obtidos com os da literatura e verificar a validade tanto do experimento como das hipóteses levantadas.

Abaixo seguem os resultados obtidos com o experimento proposto, que foi aplicado a uma turma de 38 alunos de Farmácia, na disciplina de Química Geral Experimental. Foram obtidos 19 resultados já que os estudantes trabalharam em turmas de dois.

\section{RESULTADOS OBTIDOS PELOS ALUNOS}

Para a densidade do cloreto de sódio os valores variaram entre o mínimo de $1,87 \mathrm{~g} \mathrm{~cm}^{-3}$ ao máximo de $2,16 \mathrm{~g} \mathrm{~cm}^{-3}$ (valor da literatura é de $\left.2,17 \mathrm{~g} \mathrm{~cm}^{-3}\right)^{6}$. A densidade média encontrada é $2,04 \pm 0,08 \mathrm{~g} \mathrm{~cm}^{-3}$ (DPR $\cong 4 \%)$. O erro relativo é de aproximadamente $-6 \%$. Seguindo o raciocínio mostrado acima no artigo, chega-se, com este valor de densidade, aos raios de 114 pm para o sódio e 174 para o cloreto. Estes resultados podem ser considerados surpreendentes para um experimento de tal simplicidade.

Os valores de densidade obtidos pelos estudantes apresentaram-se sistematicamente abaixo do valor verdadeiro, o que leva à indagação das possíveis causas deste fato.

Em primeiro lugar deve-se lembrar que o instrumento de medida é uma régua de plástico que, por si só, já introduz uma imprecisão de $\pm 2 \mathrm{~mm}$ (lembrar que são dois meniscos, o superior e o inferior). Isto significa que na determinação da altura da coluna de líquido deslocado $(6,2 \mathrm{~mm})$ já há uma incerteza de, pelo menos, $3,2 \%$, que contribui para o desvio observado de $4 \%$. Tem-se, também, a incerteza na determinação do perímetro etc. Entra aí, ainda, a habilidade de cada estudante.

Em segundo lugar, é importante lembrar que a determinação do volume deslocado foi feita medindo-se o perímetro externo da garrafa. No guia de laboratório há uma observação: "Neste experimento, como a parede da garrafa PET é muito fina, a sua espessura será desprezada. O erro introduzido com esta consideração é suficientemente pequeno para, nas condições do experimento, não contribuir para uma grande distorção do resultado final'. Medindo a espessura de uma garrafa PET com um paquímetro, observa-se que ela é de, aproximadamente, $0,3 \mathrm{~mm}$. Corrigindo, assim, o raio obtido usando o perímetro externo, chega-se ao valor de $4,99 \mathrm{~cm}$ contra os $5,02 \mathrm{~cm}$ originalmente admitidos levando-se em consideração a densidade média obtida. Refazendo os cálculos chega-se ao valor de densidade de 2,06 $\mathrm{g} \mathrm{cm}^{-3}$ que leva aos valores de 173 e $113 \mathrm{pm}$, respectivamente, para os raios dos íons cloreto e sódio. Portanto, o valor do raio da garrafa, neste caso, não afeta significativamente o resultado final. Outros fatores devem contribuir de modo mais importante para o fato dos resultados de densidade terem sido menores que o valor tabelado. Entre eles pode-se imaginar que tenha ficado ar preso entre os cristais ocasionando um aumento no volume de água deslocada levando, assim, a valores mais baixos que o esperado.

A reação dos estudantes, frente a este experimento na forma aqui apresentada, foi de entusiasmo desde o momento em que receberam as instruções para a realização do experimento até a obtenção dos resultados finais que se aproximam dos tabelados na literatura. Uma das provas do entusiasmo dos estudantes é que nenhum deles se esqueceu de levar o material solicitado, ou seja, as garrafas PET, sendo uma já cortada em forma de funil, os saquinhos de sal, etc.

\section{CONSIDERAÇÕES FINAIS}

O experimento proposto, apesar da extrema simplicidade e, talvez, inclusive devido a ela, é riquíssimo em informações e contribui muito para exercitar o uso de modelos e, portanto, para a formação do raciocínio científico dos alunos. O aproveitamento depende, evidentemente, de cada aluno, mas, também, muito do professor e do estímulo que este provocará em cada estudante.

No caso específico deste trabalho, partiu-se do pressuposto do conhecimento prévio da estrutura de faces centradas para o cloreto de sódio. Raciocínio análogo pode ser feito levando-se em consideração uma estrutura de corpo centrado. Evita-se fazer aqui este tratamento pois, com certeza, o colega professor poderá fazê-lo, sem grandes dificuldades, caso julgue interessante.

\section{AGRADECIMENTOS}

À Profa. Dra. M. do C. Gonçalves, do IQ da Unicamp, pela aplicação do experimento na disciplina de Química Geral Experimental.

\section{REFERÊNCIAS}

1. Tubino, M.; Quim. Nova 1983, 6, 109.

2. Tubino, M.; Simoni, J. A.; Quimica Nova na Escola 1999, nº 9, 41.

3. Atkins, P.; Jones, L.; Princípios de Química: Questionando a Vida Moderna e o Meio Ambiente, Bookman: Porto Alegre, $3^{\mathrm{a}}$ ed., 2006.

4. Mahan, B. M.; Myers, R. J.; Química, Um Curso Universitário, Ed. Edgard Blücher Ltda: São Paulo, tradução da $4^{\mathrm{a}}$ edição americana, 2002.

5. Petrucci, R. H.; Harwood, W. S.; Herring, F. G.; General Chemistry, Prentice Hall: New Jersey, $8^{\text {th }}$ ed., 2002.

6. CRC Handbook of Chemistry and Physics; Lide, D. R.,ed., CRC Press: Washington, D.C., $85^{\text {th }}$ ed, 2004-2005. 